ISSN 1981-416X

Licenciado sob uma Licença Creative Commons

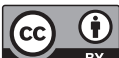

\title{
A fluência digital como possibilitadora de inclusão digital de crianças mediante ações em oficinas
}

\author{
Digital fluency as a facilitator of digital inclusion \\ of children through actions in workshops \\ La fluidez digital como facilitadora de la inclusión \\ digital de niños por acciones en talleres
}

Edjane Mikaelly Silva de Azevêdo ${ }^{[a]}$, Deise Juliana Francisco ${ }^{[b]^{*}}$

\author{
[a] Universidade Federal Rural do Semi-Árido, Mossoró, RN, Brasil \\ [b] Universidade Federal de Alagoas (UFAL), Maceió, AL, Brasil
}

\section{Resumo}

O presente trabalho é uma pesquisa de natureza qualitativa, realizada em uma escola da rede municipal de ensino, na cidade de Cruzeta/RN. Objetiva analisar como se deu o processo de fluência e inclusão digital mediante o aprender fazendo, por crianças participantes de oficina de linguagem de programação Scratch e robótica educacional. Foram utilizados como instrumentos de pesquisa observações, filmagens, fotografias e diário de campo, valendo-se da metodologia descritiva-exploratória, articulando teoria e prática realizada na oficina, do aprender fazendo e do brincar. Mediante a análise dos dados, observou-se que a linguagem Scratch e a robótica educacional contribuíram com o desenvolvimento de

*EMSA: Mestre em Cognição, Tecnologias e Instituições, e-mail: edjanemikaelly@hotmail.com DJF: Doutora em Informática na Educação, e-mail: deisej@gmail.com 
competências, como a autonomia, a autoria, o cooperativismo e a inclusão digital, além de ter proporcionado propostas que levaram os participantes a condições efetivas de se tornarem fluentes digitais.

Palavras-chave: Fluência digital. Robótica. Scratch.

\begin{abstract}
The present work is a qualitative research carried out in a public school, in the city of Cruzeta / RN. It aims to analyze how the process of digital inclusion and fluency has been achieved through learning by doing, by children participating in Scratch programming language workshop and educational robotics. Observations, filming, photographs and field diaries were used as research instruments, using the descriptive-exploratory methodology, articulating theory and practice in the workshop, of learning by doing and playing. Through the analysis of the data, it was observed that the Scratch language and educational robotics contributed to the development of competences, such as autonomy, authorship, cooperativism and digital inclusion, besides it provided proposals that led the participants to effective conditions of becoming digital fluent.
\end{abstract}

Keywords: Digital fluency. Robotics. Scratch.

\title{
Resumen
}

El presente trabajo es una investigación de naturaleza cualitativa, realizada en una escuela de la red municipal de enseñanza, en la ciudad de Cruzeta / RN. Objetivo analizar cómo se dio el proceso de fluencia e inclusión digital mediante el aprendizaje haciendo, por niños participantes de taller de lenguaje de programación Scratch y robótica educativa. Se utilizaron como instrumentos de investigación observaciones, filmaciones, fotografías y diario de campo, valiéndose de la metodología descriptiva-exploratoria, articulando teoría y práctica realizada en el taller, del aprendizaje haciendo y del juego. A través del análisis de los datos, se observó que el lenguaje Scratch y la robótica educativa contribuyeron con 
el desarrollo de competencias, como la autonomía, la autoría, el cooperativismo y la inclusión digital, además de haber proporcionado propuestas que llevaron a los participantes a condiciones efectivas de convertirse en fluentes digitales.

Palabras clave: Fluidez digital. Robótica. Scratch.

\section{Introdução}

A tecnologia vem revolucionando diversas esferas sociais, como a econômica, a política, a cultural e a educacional, comportando as novas maneiras de trabalhar, de se comunicar, de se relacionar, de aprender e de pensar (COLL; MONEREO, 2010). Para Castells (1999) e Kenski (2007), essa revolução tem contribuído para a formação da sociedade e, por este motivo, novos recursos tecnológicos têm surgido, transformando e auxiliando o novo contexto da sociedade contemporânea. Os autores afirmam que isto vem desencadeando uma nova cultura - a digital, que molda o pensar, o agir, o comunicar-se com os outros, o trabalhar e o aprender (KENSKI, 2015), podendo potencializar e promover a equidade e a qualidade na educação.

Um destaque no contexto contemporâneo é a crescente utilização das tecnologias da informação e comunicação, que podem proporcionar uma considerável melhoria no processo educacional. Entretanto, atingir esta meta exigirá novas abordagens da educação e do aprendizado que proporcionem uma sociedade de pessoas críticas e criativas, compreendendo que não é o objeto que leva à compreensão, mas esta é fruto de como o objetivo é utilizado e de como o aluno está sendo desafiado na atividade de uso desse recurso.

Em meio a tantas ferramentas tecnológicas como possíveis potencializadoras no processo de ensino-aprendizagem, algumas iniciativas vêm sendo propostas, a fim de serem apresentadas possibilidades para torná-lo mais criativo e estimulante. Dentre elas, destacam-se as linguagens gráficas de programação e a robótica educacional (LOPES, 
2008; 2010), estratégias desafiadoras e lúdicas para a promoção de aprendizagens, criatividade, criticidade, autonomia e autoria, além de serem propulsoras da fluência digital, pois a partir dessas ferramentas as pessoas manipulam, compreendem e constroem tecnologias (MARJI, 2014; SOUSA; LENCASTRE, 2014).

Diante deste cenário, e considerando o que esses recursos proporcionam para o desenvolvimento cognitivo e social das pessoas, esta pesquisa objetiva analisar como se deu o processo de fluência e inclusão digital mediante o aprender fazendo, por crianças participantes de oficina de linguagem de programação Scratch e robótica educacional, evidenciando o educando como o protagonista de suas atividades.

Esta pesquisa foi realizada em uma Escola Municipal, na cidade de Cruzeta/RN, com alunos do $6^{\circ}$ ano do Ensino Fundamental II, e faz parte de uma dissertação, apresentada e aprovada em julho de 2018, e possui a apreciação do Comitê de Ética em Pesquisa, tendo o número do parecer: 2.265.288.

\section{A linguagem gráfica de programação SCRATCH}

O Scratch é uma linguagem de programação em blocos, desenvolvida no Massachusetts Institute of Technology (MIT), Media Lab, que tem o intuito de tornar o aprendizado de programação mais fácil (MARJI, 2014) e, segundo Martins (2012), é uma versão mais robusta da linguagem de programação LOGO, criada com finalidades educacionais, com o início de suas pesquisas no Brasil na década de 80 (PRADO, 1999), entretanto, seu uso foi diminuindo em função da popularização dos programas multimídia na década de 90 .

A linguagem Scratch possibilita a criação de histórias/estórias interativas, jogos, animações, bem como seus compartilhamentos na Internet. Todas as ações podem ser realizadas a partir de comandos que devem ser agrupados em blocos, de modo lógico, como em um jogo de quebra-cabeças, e está disponível em 74 (setenta e quatro) línguas, inclusive o Português. 
Ao adentrar no ambiente é possível observar um banco de recursos no próprio programa, como sprites ${ }^{1}$ (personagens ou atores), objetos, cenas e blocos de comandos, nos quais estão inseridos os movimentos, as aparências, os sons, as canetas, os controles, os sensores, os operadores e as variáveis, permitindo que seja possível dar animação aos atores, para que tenham capacidade de cantar, dançar e interagir com os outros. De acordo com Martins (2012), com ele, é possível misturar diferentes tipos de mídias de maneira criativa, utilizando uma programação muito próxima às linguagens convencionais, entretanto, de forma lúdica, simples e intuitiva. $\mathrm{O}$ ambiente também fornece a opção de desenhar seus personagens em um espaço reservado do site, possibilitando o melhoramento da coordenação motora, já que para que se tenha êxito, o usuário deve desenhar deslizando o mouse.

Para Mendonça Neto (2013, p. 262), o Scratch "possibilita a criação de programas de maneira mais simples e dinâmica, além de estimular o raciocínio lógico, e de permitir visualizar graficamente a execução do programa criado", e em consonância a ele, Marji (2014), reflete que a maioria das linguagens de programação é baseada em texto, porém, o Scratch é uma linguagem de programação visual, no qual não é necessário digitar nenhum comando complexo, mas conectar blocos gráficos para criar as animações. Segundo Scaico et al (2013, p. 96), "o Scratch traz uma linguagem que contribui para a aprendizagem de programação através de um conceito inovador de desenvolvimento de código orientado ao design", privilegiando a criatividade e a autonomia do programador. Com o Scratch, é possível apenas puxar um bloco para que a mensagem seja emitida na tela.

1 Um sprite é um ator que irá receber comandos. “Os sprites entendem e obedecem a conjuntos de instruções que você lhes atribui" (MARJI, 2014, p. 22). 


\section{A robótica educacional}

O avanço dos conhecimentos tecnológicos tem se tornado evidente no cotidiano da sociedade contemporânea, com a modificação dos modos de vida e a promoção de transformações na sociedade, além de pressupor diversas mudanças na educação (AZEVEDO; FRANCISCO; NUNES, 2017). A robótica educacional tem um papel importante nessas mudanças, pois ela pode ser uma ferramenta valiosa para o ensino de diversas disciplinas, como a Engenharia Mecânica e Elétrica, a Inteligência Artificial, a Física, a Matemática, a Geografia, Linguagens, enfim, ela é um leque de opções interdisciplinares (AZEVEDO; FRANCISCO; NUNES, 2017).

Para Azevedo, Aglaé e Pitta (2010), a robótica educacional vem ganhando espaço aos poucos, trazendo contribuições para o processo de ensino-aprendizagem, além de se tratar de uma possibilidade para ser utilizada para auxiliar o professor em sua prática pedagógica.

A robótica vem se destacando no cenário educacional, despertando nos alunos o potencial criativo e a motivação para a descoberta. Lopes $(2008 ; 2010)$ reflete que dentre os diversos recursos tecnológicos aplicados à educação, a robótica tem sido uma das que mais avançou em termos de inovações. Porém, se produz muito referencial teórico acerca de práticas metodológicas, mas os resultados não chegam até professores e alunos, além de não existir um apoio financeiro para que seja implantado um projeto nas escolas da rede pública.

A robótica educacional é uma proposta que teve suas primeiras investigações desenvolvidas por um grupo de pesquisadores do Massachusetts Institute of Technology (MIT), liderados pelo professor Seymour Papert, no final dos anos 60 (MIRANDA, 1990; RESNICK, 1993), quando iniciaram suas pesquisas com a elaboração da linguagem LOGO.

A linguagem LOGO foi criada de forma simples, para que as crianças, mesmo as que não possuíssem conhecimento em informática, conseguissem utilizá-la. Além disso, a LOGO tem como base a 
epistemologia construtivista do processo de aprendizagem, no qual o aluno constrói suas estruturas mentais a partir de sua interação com os objetos. Segundo Prado (1999), esta linguagem possui características que fazem dela acessível a pessoas de diversas áreas e de diferentes níveis de escolaridade. Também, possui características pertencentes a três paradigmas computacionais distintos: o procedural, o orientado a objetos e o funcional, sendo mais conhecido pelo primeiro.

$\mathrm{Na}$ década de 80, Papert criou a tartaruga de solo, com base em dispositivos já existentes. Esta deveria representar figuras geométricas em um terreno plano, a partir da programação realizada por crianças com a linguagem LOGO. Com o surgimento dos computadores pessoais, a tartaruga física deu o seu lugar a uma virtual, denominada por Papert como objeto de pensar com, ampliando conhecimentos matemáticos, geométricos e de design (AZEVEDO; AGLAÉ; PITTA, 2010).

Nesta perspectiva, o processo de aprendizagem do aluno, pautado em sua reflexão sobre a ação de forma dinâmica e quase simultânea, é fundamental e demanda de novas compreensões dos alunos, que os incentive a pensar de forma mais eficiente, lúdica, prática e criativa.

\section{A fluência digital}

A fluência digital, para Resnick (2002), não é caracterizada apenas como a utilização da tecnologia. Mas, de acordo com o autor, as pessoas são apresentadas ao computador e ensinadas a como procurar informações na Internet, a como utilizar um processador de textos e a enviar um e-mail, mas isso não as torna fluentes em tecnologia. Desse modo, podemos refletir que a fluência digital acontece quando a pessoa, além de saber utilizar, consegue criar tecnologia.

Assim, o Scratch e a robótica educacional possibilitam que a habilidade de programar e construir softwares e protótipos robóticos se estabeleça em função do raciocínio lógico, possibilitando que as crianças 
consigam se apropriar da fluência digital, não apenas por ela ter grande valor na vida diária, mas por ter um efeito progressivo no aprendizado.

De acordo com Resnick (2012), para Papert, as crianças deveriam ter a capacidade de projetar, criar e se expressar com os recursos tecnológicos, como jogos e animações. Ao invés de apenas interagir, deveriam aprender a programá-los. Além de, nesse processo, "aprender habilidades importantes para resolver problemas e estratégias de design de projeto" (p. 42). Dessa forma, as crianças estariam se apropriando dessas tecnologias, o que pode ser associado ao conceito de fluência digital. Para o autor, se alguém sabe utilizar a tecnologia, mas não consegue criar, pode ser associada a uma pessoa que sabe ler, mas não sabe escrever. Resnick (2012) ainda reflete que as maiores barreiras para a fluência digital não são tecnológicas, mas culturais e educacionais, pois não somos orientados a criar, mas apenas a utilizar as tecnologias digitais. Para o autor, mudanças nesse sentido só ocorrerão se as pessoas forem incitadas a utilizar a linguagem de programação da mesma forma que utilizam os computadores em geral.

Para Resnick (2007), o Scratch e a robótica educacional têm o objetivo explícito de ajudar as pessoas a desenvolverem seu pensamento criativo, apoiando o que ele chama de espiral de pensamento criativo. Mediante a análise da espiral do pensamento, a medida em que as pessoas passam por esse processo, conseguem desenvolver seus pensamentos, criar ou desconstruir ideias e experimentá-las, testar alternativas, obter contribuições de outros e gerar novas ideias com base em suas experiências.

Conseguimos refletir que a linguagem gráfica Scratch e a robótica educacional despertam a curiosidade, a criatividade, a criticidade, a autoria, o trabalho em equipe, que, por sua vez, desencadeia a empatia, o respeito mútuo e o saber ouvir o outro. Ao conseguir a apropriação dessas ferramentas, a fluência digital passa a ter papel de propulsora geradora de conhecimentos (RESNICK, 2002; 2007), pois, a partir disso é que se aprende como construir coisas significativas com os recursos tecnológicos. 


\section{Procedimentos metodológicos}

Esta pesquisa é do tipo qualitativa, caracterizando-se como uma pesquisa-intervenção. Para que seus objetivos fossem alcançados, foram utilizados como instrumentos metodológicos análise bibliográfica, observações, filmagens, fotografias e o diário de campo, valendo-se de oficinas, as quais estão atreladas às metodologias descritiva-exploratória, articulando teoria e prática evidenciada e do aprender fazendo e brincando.

As oficinas foram divididas em três contextos e subdivididas em 10 encontros. O primeiro foi pautado na apresentação do projeto, em experimentos e experiências realizadas com os alunos acerca da lógica e da linguagem de programação em blocos Scratch. O segundo contexto refere-se à realização das oficinas acerca da robótica educacional com placas microcontroladororas UNO R3 e com kits LEGO MINDSTORMS EV3. Já o terceiro, refere-se à apresentação dos projetos para a comunidade escolar.

Para o acontecimento das oficinas, houve participação de 10 alunos de duas turmas do $6^{\circ}$ ano do Ensino Fundamental II, de uma escola municipal da cidade de Cruzeta/RN. A escolha desta série se deu por representar um período de transação entre o Ensino Fundamental I e o II.

Para que as oficinas fluíssem de acordo com o planejado, foram elaboradas cinco etapas. Durante a primeira, os participantes foram orientados acerca dos conceitos básicos da lógica de programação, atrelados também ao cotidiano, com exemplos simples, porém significativos, que contribuíram com todo o percurso. $\mathrm{Na}$ segunda, foram apresentados a linguagem Scratch, os conceitos de comandos essenciais ao uso de estruturas de controle, como as de sequência, seleção e repetição, bem como instruções condicionais, variáveis, números aleatórios e desenho de interface do utilizador.

Já na terceira, os participantes realizaram animações orientadas pela ministrante e criaram suas próprias aplicações no decorrer das etapas. Na quarta, eles foram orientados a realizar as montagens dos robôs e a como programá-los. E na quinta, programaram e montaram os robôs sozinhos, de acordo com o que planejaram. 


\section{Apresentação da pesquisa e escolha dos participantes}

Para a seleção dos participantes, foi realizado um sorteio com as pessoas que tiveram interesse em participar da pesquisa. Ao todo, foram sorteados 16 participantes (sem distinção de sexo, idade e faixa etária), entretanto, apenas 10 foram selecionados, porque a escola dispunha de 5 computadores no laboratório de informática, assim, trabalharíamos com 2 participantes por computador. A escolha foi realizada de acordo com a sequência em que foram sendo sorteados os nomes, sendo que os últimos três ficariam alocados em uma lista de reserva.

Ao serem esclarecidos acerca das regras que o sorteio iria obedecer, os objetivos da pesquisa foram apresentados para os alunos, bem como quais os benefícios e os riscos eles estariam submetidos e como estes seriam minimizados. Em seguida, foi realizada a coleta das assinaturas de quem havia sentido interesse em participar.

Após a leitura do Termo de Assentimento Livre e Esclarecido e o sorteio, foi realizada uma reunião com os responsáveis pelas crianças, para que eles consentissem a participação de seus tutelados na pesquisa. Nesta reunião foram apresentados e assinados o Termo de Consentimento Livre e Esclarecido, bem como as autorizações de coleta e divulgação de imagens e áudio.

\section{Soltando a imaginação: etapas da oficina}

Para o primeiro encontro, como os participantes não conheciam as ferramentas que seriam utilizadas, foram apresentados a uma animação criada com a linguagem Scratch, no qual um gato andava e um morcego voava. Com esta criação, foram sendo exploradas, além das funcionalidades da linguagem, as estruturas de controle do fluxo de execução, sequencial, de seleção e de repetição, com as aplicações específicas de cada estrutura. Ao iniciarmos a animação, realizamos, em conjunto, a programação do gato para que ele se locomovesse no ambiente do Scratch, que 
andasse até encontrar uma borda, e quando a encontrasse, voltasse, realizando essas ações durante um período indeterminado. Os participantes foram orientados pelas pesquisadoras a encaixar os blocos da linguagem passo a passo, e encontraram algumas problemáticas, pois o gato andava, mas ao encontrar a borda, não voltava.

Após criarmos, juntos, a programação para o gato, os participantes foram orientados a realizar a programação do morcego sozinhos. Depois de terem conseguido concluir a atividade, foram orientados a criar suas animações, com o tema que quisessem.

Um grupo, composto por meninos, desenhou com a ferramenta desenho livre, disponibilizada pelo Scratch, um campo de futebol, e conseguiram que a bola se movesse da direita para a esquerda. Ao serem questionados sobre o motivo das suas criações, eles responderam que gostavam de futebol, e que por ser algo que eles tinham afinidade, decidiram criar.

Já o segundo grupo, composto apenas por meninas, criou uma apresentação com alguns elementos que não eram coerentes ao olhar das pesquisadoras, e ao serem questionadas acerca do motivo de terem utilizado quatro personagens, sendo uma bailarina, um caranguejo, um cachorro, uma menina, e um plano de fundo com uma praia, responderam que os elementos representavam os gostos de cada uma. Já o plano de fundo escolhido, o mar, é porque ambas gostam de praia e o caranguejo por estarem trabalhando com um ambiente marinho.

O terceiro grupo, formado por meninos, criou algo que nem eles souberam explicar o motivo, um robô jogando futebol na lua e dois alienígenas comendo salgadinhos. Eles comentaram que os personagens iriam comer batata frita na lua e o robô iria jogar futebol.

Já o quarto grupo, composto por meninas, criou uma festa de aniversário para o gato, e exploraram diversos blocos do Scratch. Ao perceber que elas foram além dos outros grupos, foram indagadas sobre a curiosidade que tiveram em mexer em funções da linguagem, inclusive algumas que não haviam sido apresentadas. As participantes responderam que sentiram curiosidade em saber quais ações elas poderiam proporcionar. Podemos analisar que as alunas sentiram-se instigadas a explorar 
o Scratch e a diferenciar sua animação. Foi perceptível alguns erros no código, mas as participantes foram além do que lhes foi apresentado, e conseguimos observar a ciência sendo construída, como molas propulsoras a curiosidade e a espontaneidade.

No segundo encontro, os participantes foram apresentados a uma animação de calculadora que realizava as quatro operações básicas da matemática (somar, subtrair, dividir e multiplicar). Com esta animação, eles foram ensinados a criar variáveis e a utilizar operadores lógicos. Contudo, foi possível perceber que todos os grupos criaram o design de suas calculadoras de diferentes maneiras, não se prendendo ao modelo apresentado, demonstrando interação com a linguagem e com o ambiente ao qual estavam inseridos.

No terceiro encontro, foi apresentado aos participantes a criação de um quiz matemático (aplicação envolvendo perguntas e respostas), no qual o programa deveria exibir números e operações aleatórios para que o usuário inserisse uma resposta. Nesta programação, assim como na calculadora, eram necessários dois números para que fosse possível efetuar as operações, ou seja, três variáveis distintas. Durante a apresentação, o personagem deveria mostrar uma mensagem de boas-vindas aos jogadores e sortear os números, então o usuário digitaria a resposta e, caso estivesse correta, o sistema deveria adicionar 10 pontos e passar para a próxima pergunta, caso não, a implementação deveria avisar que a resposta estava incorreta e informar a correta. Todas as respostas corretas deveriam ser armazenadas para uma pontuação final de acertos.

Já no quarto encontro, houve o questionamento aos participantes se acreditavam que conseguiriam criar alguma animação sozinhos. Todos falaram que não, mas a partir de seus desenvolvimentos anteriores, era perceptível que conseguiriam ir além do que acreditavam. Então, uma nova indagação foi feita, se havia algo que eles gostariam de criar, porém, os alunos continuaram em silêncio.

Tendo em vista que os participantes eram crianças e que no início de 2017 havia estreado uma animação da Disney mundialmente famosa, Moana - Um mar de aventuras, houve um questionamento aos 
participantes se conheciam. Todos disseram que sim. Sendo assim, foi solicitado aos alunos que fizessem um grande grupo e fossem discutir sobre um jogo com os personagens do filme. As principais coisas a se pensar eram: o que eles queriam e como o criariam. A realização desta reunião contou com o tempo de 20 minutos.

Ao fim do tempo determinado, algumas ideias foram lançadas para que o objetivo da criação fosse alcançado em tempo. Uma foi a de criar um jogo onde Moana iria ganhar pontos a cada coração de Tefiti que a tocasse, e iria perder caso algum Kakamora (uma tribo formada por cocos) a atingisse. Para termos uma visão abrangente do projeto, uma das participantes da oficina foi ouvindo as sugestões dos colegas e desenhando em um papel como seria a animação. A personagem Moana iria se deslocar para a esquerda e para a direita e o coração de Tefiti e os Kakamora iriam realizar o movimento semelhante ao de deslocamento de cima para baixo, pois seriam encaixados em posições aleatórias positivas no eixo y, e sequenciados a seguirem posições negativas no mesmo eixo, no plano cartesiano. $\mathrm{O}$ desafio da Moana seria tocar o máximo de corações para ganhar 1 ponto por toque, e desviar dos Kakamora, para que não perdesse pontos.

Ao serem colocados à prova para decidirem em conjunto sobre a realização de uma animação, os participantes conseguiram visualizar e esquematizar como o jogo deveria ser representado, e mesmo sem saber, discutiram e nos remeteram a questões de design e de interação humano-computador através dos princípios de Gestalt ${ }^{2}$, bem como pensaram em três tipos de ações para os atores.

Podemos refletir, junto com Leitão (2010), que o brincar com artefatos digitais potencializou o imaginário, possibilizando a cooperação e autonomia, além de assegurar as peculiaridades dos participantes na construção do conhecimento.

No quinto encontro, as crianças foram apresentadas às placas microcontroladoras UNO R3 e a seus periféricos (jumpers, protoboard,

2 Na interação humano-computador, os princípios de Gestalt são aplicados ao design e se dividem em 06 (seis): proximidade, boa continuidade, simetria, similaridade, destino comum e fecho. 
resistores, sensor ultrassônico e leds). Neste encontro, foi preciso orientá-los acerca de uma linguagem de programação diferente, a Linguagem C. Como os participantes já haviam construído a lógica com a linguagem Scratch, precisaram apenas de algumas orientações, e conseguiram programar em uma linguagem com base na Língua Inglesa sozinhos. Os participantes criaram dois protótipos, onde no primeiro um led deveria acender, e no segundo um farol deveria funcionar com três leds, alternando o tempo entre acender e apagar.

No sexto encontro, as crianças criaram um circuito de leds que deveriam ser comandados via Bluetooth do celular. Neste momento, a única ajuda que pediram foi acerca da conectividade do módulo Bluetooth, pois já conheciam a programação e suas funções, bem como as montagens corretas.

Já no sétimo encontro, as crianças foram apresentadas aos kits LEGO EV3, com a ajuda de um carrinho seguidor de linha e uma aranha robótica. Os participantes foram orientados acerca da linguagem em blocos do LEGO, e rapidamente conseguiram associá-la às linguagens passadas, pois haviam conseguido compreender a lógica. Eles foram orientados a remontar os robôs e a criar programações de acordo com o que quisessem, e conseguiram programar a aranha para andar e desviar de obstáculos e o carro para andar e girar.

No oitavo encontro, a turma foi dividida em dois grupos e houve um pedido para que as crianças escolhessem algo para montar e depois programar. Um grupo escolheu montar um carro e o outro uma cobra. Neste encontro, a concentração era muito grande. Como as montagens eram com muitas peças, os participantes não conseguiram montar tudo neste encontro, então a conclusão foi efetuada no nono encontro, tanto as montagens quanto as programações. E no décimo encontro realizamos a mostra das atividades para a comunidade escolar, no qual eles explicaram todas as ações desenvolvidas por eles durante o percurso nas oficinas. 


\section{Resultados e discussões}

Os participantes realizaram trabalho em equipe em todas as etapas da oficina, incentivando o ouvir o outro, a autonomia, a análise da realidade a partir da confrontação de ideias e a negação delas, gerando o resultado dessa confrontação, como um ciclo, seguindo uma linha metodológica no qual os participantes aprenderam fazendo, brincando e discutindo.

Durante o percurso da oficina, os participantes foram apresentados a recursos tecnológicos e orientados acerca do que é a lógica, a linguagem de programação em blocos Scratch e a robótica educacional, e foram apresentando, de forma gradativa, um processo de fluência digital, no qual a pessoa não deve apenas saber como usar as ferramentas tecnológicas, mas também a como construir coisas significativas com elas (RESNICK, 2002), ou seja, se apropriar do recurso.

Foi notável que os participantes foram se apropriando das ferramentas propostas desde o primeiro encontro, ao explorarem possibilidades não apresentadas a eles, no programa Scratch, como códigos dispostos em abas não exploradas e a ferramenta desenho livre. Ainda, criaram animações que representaram o que eles quiseram, sentiram e imaginaram no momento da ação, que sem a explicação deles, as pesquisadoras não conseguiriam compreender, como a animação criada com um robô jogando futebol na lua, e um ser imaginário comendo salgadinhos e oferecendo para outro, dialogando.

$\mathrm{Na}$ criação da calculadora interativa, os participantes não ficaram presos ao que as pesquisadoras sugeriram, construíram das mais diversas, de modos diferentes, cada uma com sua particularidade. Ao criarem o jogo com os personagens do filme Moana - Um mar de aventuras, eles se reuniram, discutiram e desenharam como queriam que a animação fosse projetada e utilizaram, mesmo sem perceber, questões de design e de interação humano-computador, através dos princípios de Gestalt, pois se preocuparam com todos os detalhes que estariam expostos na tela, tentando torná-lo o mais agradável visualmente possível. Houve apenas uma orientação durante a programação, mas os responsáveis pelos códigos foram os 
alunos, desde a idealização até sua conclusão. No decorrer da feitura foram surgindo algumas dúvidas, principalmente na matemática aplicada para que a Moana ganhasse e perdesse pontos, mas ao serem orientados, perceberam o que deveria ser realizado, que seria inserir o - 1 (número 1 negativo) para perder e o 1 (número 1 positivo) para ganhar os pontos.

Ao serem iniciados nas práticas da robótica, as crianças tiveram contato com a linguagem $C$ e com componentes eletrônicos. Os participantes surpreenderam em relação a isso, pois conseguiram programar mesmo em Língua Inglesa. Ao serem orientados na programação para acender e apagar um led, se apropriaram da linguagem de maneira que, sozinhos, compreenderam que ao desencadearem sequencialmente os comandos, colocarem os leds na protoboard e a encaixarem os jumpers nas portas digitais iguais às da programação, conseguiriam que mais luzes acendessem. Perceberam, ainda, que um dos códigos comandava o acender e apagar do led, então conseguiram utilizá-lo de maneira que o circuito criado por eles piscasse.

Foi possível constatar, também, que em apenas um encontro para a orientação acerca da linguagem em blocos utilizada pelo programa LEGO M. EV3, as crianças perceberam que tudo o que haviam aprendido acerca da lógica de computação e da criação de algoritmos era aplicado para aquele tipo de linguagem.

Durante as montagens com os kits da LEGO, percebemos que os participantes criaram robôs diferentes, um grupo montou uma cobra, e não é possível afirmar, mas, provavelmente optaram por esta montagem por este animal ser predominante na região a qual estão inseridos, tendo em vista que um dos componentes reside na zona rural da cidade. Ainda, enquanto criavam, perceberam que ela não conseguiria se locomover com os pneus que estavam nela, então a analisaram e tiveram a ideia de remontá-la, com outros pneus maiores e mais distantes do bloco EV3 Bric, possibilitando uma melhor desenvoltura do robô. Então, se apropriaram do recurso, refletiram e reinventaram uma maneira melhor de locomoção para o robô.

Foi possível perceber, ainda, que além de ser um fator auxiliador na formação do processo cognitivo dos participantes, estas ferramentas 
também foram uma forma de inclusão social e digital, de forma que eles puderam conhecer e utilizar recursos, como o computador e softwares antes desconhecidos, possuindo dessa maneira acesso ao conhecimento e a lidar com novas mídias e aparelhos.

Mediante aos dados analisados, percebemos que os participantes foram aprendendo fazendo e brincando, pois não foram impostos a criarem. Foi preciso criar junto com eles algumas animações, para que conseguissem compreender os diferentes processos envoltos às ferramentas apresentadas, entretanto, eles sentiram vontade de criar determinadas aplicações e montagens dos robôs e não seguiram um padrão imposto a eles.

Foram perceptíveis as diversas mudanças ocorridas durante a oficina, como a configuração da autonomia, ao criarem suas aplicações e montagens robóticas por conta própria, o trabalho em equipe e o cooperativismo, ao se unirem durante os processos, tendo maior destaque durante a feitura do jogo da Moana, onde discutiram, dialogaram e desenharam um rascunho de como este jogo deveria ser montado e programado; a criticidade, reflexividade e criatividade, no qual foram deixados livres para criarem e colocarem na tela ou nas montagens, o que estavam sentindo ou as suas vivências. Assim, podemos perceber a fluência digital alcançada proporcionada pelas linguagens de programação apresentadas e pela robótica educacional.

Podemos refletir, ainda, que a atenção é necessária para o aprendizado, e de que é possível a aprendizagem da atenção também no espaço escolar, por intermédio do estímulo, da novidade e da influência exercida pelas necessidades dos participantes, potencializando o pensamento, a criticidade, a autonomia e a criatividade. Quando a brincadeira se torna algo relacionado com o aprendizado, torna-se participativa, instigante, contribuindo para a concentração, pois o brincar possui funções estimulantes acerca de atividades, com o intuito de desenvolver a criatividade, o foco, a concentração e a atenção, permitindo mais autonomia da criança. 


\section{Considerações finais}

Diante das discussões expostas neste trabalho, verificou-se por meio das observações, das filmagens, das fotografias, do diário de campo e das entrevistas realizadas com os participantes da pesquisa, que no decorrer da oficina, foram nítidos o desenvolvimento e a potencialização do trabalho em equipe, da autonomia, da liderança, da criticidade, da criatividade e da curiosidade ao procurarem funções não ensinadas a eles e o ouvir e respeitar as opiniões diversas dos colegas.

É possível refletir que os participantes compartilharam conhecimentos e se propuseram a ajudar os colegas em diversos momentos, caracterizando o sentimento de cooperativismo, causando melhores oportunidades para os demais e contribuindo com a construção cognitiva de ambos. Se destaca, ainda, o que está relacionado diretamente à própria construção da democracia, pois em todos os momentos da oficina os participantes decidiram em conjunto sobre quais aplicações no Scratch deveriam criar e como iriam concretizá-las, bem como as decisões tomadas acerca da construção e programação dos robôs.

Nesta perspectiva, o processo de aprendizagem dos participantes, pautada em suas reflexões sobre a ação de forma dinâmica e quase simultânea, é fundamental e demanda de novas compreensões, assim, incentivando-os a pensarem de forma mais eficiente, lúdica, prática e criativa para resolverem os problemas gerados.

Por fim, diante dos resultados obtidos durante os encontros, conseguimos perceber que a linguagem de programação Scratch e a robótica educacional, através do brincar e do aprender fazendo, possibilitaram o desenvolvimento de habilidades para a resolução de problemas lógicos, o estímulo a criatividade, ao pensamento crítico, a autonomia e ao trabalho em equipe, a ampliação da familiarização com as tecnologias digitais, e a criação de protótipos robóticos. Além disso, foi possível potencializar o desenvolvimento de pensamentos mais ágeis e a formulação de ideias, testando alternativas e trabalhando de maneira colaborativa, possibilitando 
as características necessárias para a incorporação de instrumentos tecnológicos modernos em sala de aula com facilidade de uso e de baixo custo.

\section{Referências}

AZEVEDO, S.; AGLAÉ, A.; PITTA, R. Curso introdutório sobre uso da robótica pedagógica no contexto escolar. Anais... Ciências do Mar: herança para o futuro. UFRN, Natal/RN 65ª reunião anual da SBPC, 2010. Disponível em: <http://www. sbpcnet.org.br/livro/62ra/minicursos.htm>. Acesso em: 03 abr. 2017.

AZEVÊDO, E. M. S. de; FRANCISCO, D. J; NUNES, A. O. O Avanço das publicações sobre a robótica educacional como possível potencializadora no processo de ensino-aprendizagem: uma revisão sistemática da literatura. Revista Educacional Interdisciplinar, v. 6, n. 1, 2017. Disponível em: <https://seer.faccat.br/index. php/redin/article/view/623/479>. Acesso em: 1 mai. 2018.

CASTELLS, M. A revolução da Tecnologia da Informação. In: CASTELLS, M. A sociedade em rede. 8. ed. São Paulo: Paz e Terra, 1999. v. 1.

COLL, C; MONEREO, C. As tecnologias da informação e da comunicação e os processos de desenvolvimento e socialização. In: COLL, C; MONEREO, C. Psicologia da educação virtual: Aprender e ensinar com as tecnologias da informação e da comunicação. Porto Alegre: Artmed, 2010. p. 47-65.

KENSKI, V. M. Tecnologias também servem para fazer educação. Educação e tecnologias: o novo ritmo da informação. Campinas: Papirus, 2007. p. 42-61.

KENSKI, V. M. Educação e Internet no Brasil. In: THEMOTEO, R. J. (org). Internet e sociedade. Edição Cadernos Adenauer XVI, Rio de Janeiro, n. 3, abr. 2015. p. 133150. Disponível em: <https://www.researchgate.net/publication/281121751_ Educacao_e_Internet_no_Brasi $>$. Acesso em: 19 abr. 2017. 
LEITÃO, R. L. A dança dos robôs: qual a matemática que emerge durante uma atividade lúdica com robótica educacional? 2010. 87 f. Dissertação (Mestrado) - Universidade Bandeirante de São Paulo, Programa de Pós-Graduação em Educação Matemática, 2010.

LOPES, D. Q. A exploração de modelos e os níveis de abstração nas construções criativas com robótica educacional. 2008. 326 f. Tese (Doutorado) - Universidade Federal do Rio Grande do Sul, Faculdade de Educação, Programa de Pós-Graduação em Informática na Educação, 2008.

LOPES, D. Q. Brincando com robôs: desenhando problemas e inventando porquês. Santa Cruz do Sul: EDUNISC, 2010. 116 p.

MARJI, M. Introdução ao Scratch. In: MARJI, M. Aprenda a programar com o Scratch: Uma introdução visual a programação com jogos, arte, ciência e matemática. São Paulo: Novatec. 2014. p. 21-45.

MARTINS, A. R. de Q. Usando o Scratch para potencializar o pensamento criativo em crianças do ensino fundamental. 2012. 113 f. Dissertação (Mestrado em Educação) - Universidade de Passo Fundo, 2012.

MENDONÇA NETO, V. dos S. A utilização da ferramenta Scratch como auxílio na aprendizagem de lógica de programação. In: II Congresso Brasileiro de Informática na Educação (CBIE 2013), 2, 2013, São Luís. Anais... São Luís: UICAMP, 2013. p. 262.

MIRANDA, G. L. Linguagem LOGO. PEDU - Artigos em revistas nacionais. p. 117120. 1990. Disponível em: <http://repositorio.ispa.pt/handle/10400.12/2860. 1990>. Acesso em: 03 abr. 2017.

PRADO, M. E. B. B. O uso do computador na Formação do Professor: Um enfoque reflexivo da prática pedagógica - Coleção Informática para mudança na escola. Brasília, DF: ProInfo-SEED-MEC, 1999. 102p. Disponível em: <http://www.dominiopublico.gov.br/download/texto/me003145.pdf >. Acesso em: 30 abr. 2017. RESNICK, M. Behavior: construction kits. Comunications of the ACM, v. 36, n. 7. p. 64-71, jul. 1993. 
RESNICK, M. Rethinking Learning in the Digital Age. In: KIRKMAN, G. S; CORNELIUS, P. K; SACHS, J. D; SCHWAB, K. (Orgs). The Global Information Technology Report: Readiness for the Networked Word. Oxford: Oxford University Press, 2002.

RESNICK, M. Sowing for a More Seeds the Creative Society. Learning \& Leading with Technology, dec./jan 2007-2008. Available in: <http://web.media.mit. edu/ mres/papers/Learning-Leading-final.pdf>. Access in: 1 abr. 2017.

RESNICK, M. Reviving Papert's Dream. Educational Technology, v. 52, n. 4, p. 4246. 2012.

SCAICO, P. D; LIMA, A. A. de; et al. Ensino de Programação no Ensino Médio: Uma Abordagem Orientada ao Design com a linguagem Scratch. Revista Brasileira de Informática na Educação, v. 21, n. 2, p. 92-103, 2013. Disponível em: <http://www. br-ie.org/pub/index.php/rbie/article/view/2364/2132〉. Acesso em: 17 abr. 2017.

SOUSA, R. M; LENCASTRE, A. Scratch: uma opção válida para desenvolver o pensamento computacional e a competência de resolução de problemas. Anais... II Encontro sobre Jogos e Mobile Learning. Braga: CIEd, 2014. Disponível em: <http:// repositorium.sdum.uminho.pt/handle/1822/29944>. Acesso em: 06 abr. 2017.

Recebido: 01/08/2018

Received: 08/01/2018

Recibido: 01/08/2018

Aprovado: 10/09/2018 Approved: 09/10/2018 Aprobado: 10/09/2018 